\title{
TRADUÇÃO
}

\section{Notas sobre uma sociologia do bullying: Homofobia de homens jovens como socialização de gênero ${ }^{1}$}

\section{J. Pascoe ${ }^{2}$}

Tradução: Tálisson Melo de Souza ${ }^{3}$

\section{Resumo}

Discursos populares e acadêmicos enquadram o bullying como algo que uma criança homofóbica dirige a outra, uma pessoa gay, lésbica ou bissexual, geralmente a primeira estando em posição mais elevada em relação a segunda, e com resultados frequentemente desastrosos. Este artigo destrincha esses discursos na atualidade e enfatiza o importante papel de interações agressivas em jogo na socialização de gênero entre meninos. A partir de um estudo de caso de bullying homofóbico entre adolescentes do sexo masculino, este artigo sugere que o estudo desse tipo de agressões é menos importante no que tange patologias individuais e mais relevante como uma forma de socialização de gênero e um mecanismo pelo qual a desigualdade de gênero é reproduzida. Uma abordagem do bullying focada na desigualdade privilegiaria o exame das interações, ao invés de qualidades individuais de agressores e vítimas; em vez de presumir um equilíbrio de poder entre iguais, investigaria as várias relações em que se dão tais interações agressivas, como as amizades; e estabeleceria um novo vocabulário do bullying para ser compreendido como um problema social que não está restrito a relações de pessoas jovens, mas reflete desigualdades estruturais bem mais amplas.

Palavras-chave: Homofobia. Bullying. Socialização de gênero. Masculinidade. Juventude.

\section{Notes on a Sociology of Bullying: Young Men's Homophobia as Gender Socialization}

\begin{abstract}
Popular and academic discourses frame bullying as something that one, often high status, homophobic kid directs at another, often lower status, GLB young person, frequently with devastating

1 Este artigo foi publicado originalmente no número inaugural do QED: A Journal in GLBTQ Worldmaking, (C 2013 Michigan State University.

2 C. J. Pascoe é professora associada do Departamento de Sociologia da Universidade de Oregon, nos Estados Unidos. É autora do livro premiado "Dude, You're a Fag: Masculinity and Sexuality in High School" (2007). Vem escrevendo extensamente sobre o uso de novos meios de comunicação por jovens. Sua pesquisa atual aborda práticas e culturas românticas de pessoas jovens.

3 Tálisson Melo de Souza é doutorando no Programa de Pós-graduação em Sociologia e Antropologia (PPGSA) da Universidade Federal do Rio de Janeiro (UFRJ).
\end{abstract}


results. This article unpacks current popular and academic discourses of bullying. In doing so it highlights the important role these aggressive interactions play in boys' gender socialization. Using a case study of homophobic bullying among teenage boys in adolescence this article suggests that studying homophobic bullying is less important as an individual pathology and more salient as a form of gender socialization and a mechanism by which gender inequality is reproduced. An inequality focused frame for bullying would privilege examining interactions, rather than individual qualities of bullies and victims; would investigate the various relationships in which these aggressive interactions take place, such as friendships rather than presuming a peer power imbalance; and flesh out a new vocabulary of bullying such that it is understood as a social problem that is not unique to young people, but reflects larger structural inequalities.

\section{Keywords: Homophobia. Bullying. Gender socialization. Masculinity. Youth.}

\section{Notas sobre una Sociología del Bullying: Homofobia de Hombres Jóvenes como Socialización de Género}

\section{Resumen}

Discursos populares y académicos encuadran el bullying como algo que un niño homofóbico dirige a otro, una persona gay, lesbiana o bisexual, generalmente la primera en posición más elevada en relación a la segunda, y con resultados frecuentemente desastrosos. Este artículo evalúa esos discursos en la actualidad y enfatiza el importante rol de las interacciones agresivas en juego en la socialización de género entre niños. A partir de estudios de caso de bullying homofóbico entre adolescentes del sexo masculino, este artículo sugiere que el estudio de ese tipo de agresiones es menos importante en respecto a patologías individuales y más relevante como una forma de socialización de género y un mecanismo por el que la desigualdad de género es reproducida. Un abordaje del bullying enfocado en la desigualdad privilegiaría el análisis de las interacciones, al contrario de cualidades individuales de agresores y víctimas; en lugar de presumir un equilibrio de poder entre iguales, investigaría las varias relaciones en que se dan tales interacciones agresivas, como las amistades; y establecería un nuevo vocabulario del bullying para ser comprendido como un problema social que no está restringido a relaciones de personas jóvenes, sino que reflete desigualdades estructurales muy más amplias.

\section{Palabras-clave: Homofobia. Bullying. Socialización de género. Masculinidad. Juventud.}

Quando comecei a estudar masculinidade na adolescência, a uma década atrás, não me ocorreu que acabaria escrevendo um livro, Dude, You're a Fag: Masculinity and Sexuality in High School, que trataria essencialmente do bullying (PASCOE, 2007). Este livro investiga como jovens estadunidenses entendem, encenam e resistem a definições contemporâneas de masculinidade. Durante um ano e meio pesquisando sobre entendimentos e práticas de masculinidade entre pessoas jovens numa escola de ensino médio da classe trabalhadora, River High, no norte da
Califórnia, observei a maneira como meninos vêm a pensar a si mesmos e os outros como aceitavelmente masculinos amplamente baseados no assédio homofóbico contra outros meninos e no assédio sexual contra meninas. Em outras palavras, identifiquei que grande parte do que constituía a masculinidade de adolescentes eram práticas que se pareciam muito com o bullying. Curiosamente, no entanto, me referi ao conceito de bullying apenas três vezes no texto resultante.

Com a vantagem de estar em 2013 e poder olhar para trás, isso parece estranho. No The New 
York Times, as menções ao bullying aumentaram de 160 em 2000 para $6730 \mathrm{em} 2012^{4}$. A Casa Branca agora organiza fóruns e mantém um website sobre bullying. Impulsionado por denúncias de crueldade juvenil, Lady Gaga fundou a Born This Way Foundation para promover generosidade e resiliência. Em reação a um bullying homofóbico aparentemente epidêmico, o It Gets Better Project (2013) lançou vídeos inspiradores à juventude LGBTQ. Um documentário aclamado pela crítica, "Bully" (2011), retrata as consequências devastadoras do bullying sobre vítimas jovens. Um autor inclusive afirma que vivemos em uma sociedade caracterizada pelo bullying, uma verdadeira "sociedade bully" ["sociedade que pratica o bullying"] (KLEIN, 2012).

É verdade que pelos últimos anos nós temos ouvindo muitas estórias trágicas de jovens que suicidaram devido ao bullying, especificamente o bullying homofóbico. Tyler Clementi, Eric Mohat, Carl Joseph Walker Hoover, Jaheem Herrera, Billy Lucas, Jadin Bell, entre uma miríade de outros anônimos, são alguns que saíram deste mundo por suas próprias mãos, incapazes de suportar o bullying homofóbico direcionado a eles. Sofreram essa forma de assédio independentemente de sua autoidentificação como homossexuais ou heterossexuais (KIMMEL; MAHLER, 2003). Suas estórias tornaram-se gritos de guerra contra a homofobia e o bullying homofóbico.

Até mesmo as estatísticas mais apressadas indicavam que o bullying homofóbico é um problema. Nacionalmente, $93 \%$ dos jovens escutam insultos homofóbicos ocasionalmente; $51 \%$ deles ouvem isso diariamente (NATIONAL MENTAL HEALTH ASSOCIATION, 2002). Também evidenciam majoritariamente que essa forma de assédio tem base no gênero - linguagem e atitudes homofóbicas são desproporcionalmente empregadas por meninos (POTEAT; RIVERS, 2010). De fato, meninos heterossexuais frequentemente são alvos desses insultos (Pascoe, 2007). Os meninos usam esses adjetivos mais que as meninas e os levam muito mais a sério (THURLOW, 2001). Talvez não surpreendentemente, $90 \%$ dos tiroteios aleatórios em escolas envolviam meninos que se autoidentificam como heterossexuais e que foram incessantemente humilhados com comentários homofóbicos (KIMMEL; MAHLER, 2003). Essas estatísticas não são casuais. Indicam que a homofobia e a linguagem homofóbica são centrais para a constituição de identidades masculinas heterossexuais contemporâneas (KEHLER, 2007; LEVY, CORTESI, GASSER; BEATON; CASEY; NOLAN, 2012; PASCOE, 2007; POTEAT; KIMMEL; WILCHINS, 2011). Não são apenas crianças gays que sofrem bullying por serem homossexuais; esse tipo de bullying homofóbico é uma parte da socialização de gênero de meninos em comportamentos, práticas, atitudes e disposições normativamente masculinos (PASCOE, 2007). Ou seja, é através desse comportamento homofóbico que os meninos aprendem o que é "ser um menino".

Compreendendo o bullying homofóbico como parte do processo de socialização de gênero de meninos sugere que o atual discurso sobre bullying precisa ser reformulado. Conceber o comportamento agressivo de meninos apenas como "bullying" pode elidir o modo complexo como suas interações agressivas são parte central de um processo de socialização de gênero que mantém e reproduz a desigualdade de gênero e sexual. Vendo o bullying como reprodução interacional de desigualdades estruturais mais amplas indica que os discursos popular e acadêmico correntes sobre bullying perde elementos importantes, resultando em reações amplamente individualizadas e simbólicas, ao invés de estruturais e sistêmicas.

Neste artigo, sugiro que uma análise crítica da desigualdade pode ser realizada através do desenvolvimento de uma sociologia do bullying. Uma sociologia do bullying abordaria essas interações agressivas não necessariamente como produto de patologias individuais mal ajustadas socialmente, mas como a reprodução interacional de desigualdades mais amplas. Uma sociologia do bullying deslocaria a unidade de análise do indivíduo para a interação agressiva em si, observar os contextos sociais em que o bullying ocorre, questionar os sentidos produzidos por tais interações e compreendê-las não somente na 
esfera da juventude. Dessa maneira, explicaria as forças sociais, desigualdade institucionalizada e normas culturais que reproduzem a desigualdade. Usando interações homofóbicas de homens jovens como um estudo de caso particular, vou traçar neste artigo a discussão acadêmica atual acerca do bullying, examinar o processo de produção de sentidos no bullying homofóbico entre homens jovens, e esquematizar uma sociologia do bullying. Isso deve expandir o atual debate sobre o bullying, não só em termos de gênero e sexualidade, como também em relação a outras dimensões da desigualdade, como tipo físico, raça e classe.

\section{Abordando o bullying}

O entendimento atual popular e acadêmico do bullying, suas causas, definições, participantes, consequências e soluções são majoritariamente abordadas em pesquisas psicológicas. A literatura se restringe a uma definição estreita que limita o tipo de interações agressivas entendidas como bullying. É também amplamente focada sobre variáveis de dimensão individual relativos aos agressores, às vítimas, causas e efeitos do bullying.

A maior parte dos estudos sobre o bullying tem sido influenciada pela definição de Dan Olweus (1993). Essa definição apoia-se em três características - a intencionalidade do agressor, um desequilíbrio de poder entre o agressor e a vítima, e a repetição de interações agressivas (FINKELHOR; TURNER; HAMBY, 2012. LEVY et al., 2012). No entanto, legalmente ${ }^{5}$, coloquialmente, e em termos de políticas públicas, o significado de "bullying" frequentemente varia (HILTON; ANGELA-COLE; WAKITA, 2010. LEVY et al., 2012). Acadêmicos apontam que pessoas jovens costumam entender $\mathrm{o}$ bullying de forma diferente dos adultos ${ }^{6}$. Outros acadêmicos sugerem que há formas de bullying - direto, verbal, físico, assédio verbal e sexual, por exemplo (BEATY; ALEXEYEV, 2008) -, não considerados pela definição de Olweus. $\mathrm{Na}$ falta de uma caracterização universal e pelas limitações impostas pela definição de Olweus, pesquisadores vêm buscando aprofundar e refinar a compreensão do bullying, pois é "uma desvantagem organizar um campo em torno de um conceito cuja definição é tão difícil de apontar" (FINKELHOR et al., 2012).

Dada a dificuldade de definir o assunto (LEVY et al., 2012), é também muito complicado prover uma imagem exata de sua prevalência. As taxas alegadas de bullying variam de $10-35 \%$ a $70 \%$ de jovens (FINKELHOR et al., 2012; LEVY et al., 2012; BEATY; ALEXEYEV, 2008). Embora o bullying na Internet pareça ter aumentado nos anos 2000, o bullying em geral parece ter diminuído desde 1992 (FINKELHOR, 2013).

Jovens são vítimas de bullying por vários motivos. O gatilho mais comum para o bullying é a aparência da vítima (FRISÉN; JONSSON; PERSSON, 2007), frequentemente em relação ao tipo físico (tamanho do corpo). Jovens qualificados como obesos são mais propensos a vivenciar bullying de seus pares, família e professores (GRIFFITHS; WOLKE; PAGE; HORWOOD, 2005; PUHL; PETERSON; LUEDICKE, 2012). Outro grupo de vítimas frequentes é o da juventude GLBTQ e de jovens com deficiências (LEVY et al., 2012.).

Consequências negativas e de longo prazo são associadas ao bullying e à retaliação (FINKELHOR et al., 2012; HILTON et al., 2010; NANSEL; OVERPECK; PILLA; RUAN; SIMONS-MORTON; SCHEIDT, 2001; PUHL; LUEDICKE, 2012; PUHL et al., 2012). O bullying está ligado ao desenvolvimento antissocial e às elevadas taxas de desordem psiquiátrica em adultos (BENDER; LÖSEL, 2011; COPELAND; WOLKE; ANGOLD; COSTELLOM, 2013). Vítimas que podem ter sido mais intensamente agredidas em idade mais elevadas têm maiores riscos de pensamento e comportamento suicida (LEVY et al., 2012). O bullying baseado no viés pessoal parece ter um impacto mais negativo do que outras formas de bullying (Ibid.).

O comportamento que inclui a prática de 
bullying tem relação com a idade, classe, grupo de pares, estado emocional, gênero e autoestima (BEATY; ALEXEYEV, 2008; SALMIVALLI; VOETEN, 2004; SEALS; YOUNG, 2003). Práticas de bullying variam por idade, culminando nos anos do ensino médio e então diminuindo com a idade (FRISÉN et al., 2007; LEVY et al., 2012). Normas de grupo e atitudes individuais também influenciam comportamentos relacionados ao bullying (SALMIVALLI; VOETEN, 2004). Os que praticam bullying são frequentemente populares, indivíduos de alto status que são líderes, especialmente na pré-adolescência (JUVONEN; WANG; ESPINOZA, 2010). Dito isto, eles também vêm de um estrato de grupos sociais no ambiente escolar (LEVY et al., 2012; VAILLANCOURT; HYMEL; McDOUGALL, 2013; PEETERS; CILLESSEN; SCHOLTE, 2010). Sua posição social está relacionada ao tipo de bullying em que se envolvem (PEETERS et al., 2010).

Resultados acerca dos estados emocionais de perpetradores e vítimas de bullying estão combinados e confundidos. Embora Nansel et al. (2001) afirme que o ajuste psicossocial mais precário caracterize os agressores enquanto Seals e Young (2003) mostrem que altos graus de depressão são encontrados tanto nas vítimas quanto nos assediadores, outros demonstram que estes em geral não têm baixa autoestima e sentem-se bem consigo mesmos e suas interações com colegas (VAILLANCOURT et al., 2013). Isso contraria as compreensões populares de uma autoimagem desqualificada (FRISÉN et al., 2007).

Há diferenças marcadas pelo gênero nas práticas de bullying (FRISÉN et al., 2007; PESKIN; TORTOLERO; MARKHAM, 2006. SEALS; YOUNG, 2003). De maneira simplificada, meninos são mais assediadores que meninas tanto em ambientes virtuais quanto fora deles (LI, 2006). Eles também são vítimas mais frequentemente que as meninas (FRISÉN et al., 2007; LEVY et al., 2012; SEALS; YOUNG, 2010). Meninos estão mais sujeitos a se envolver em bullying de tipo verbal e físico (PESKIN et al., 2006). Ainda assim, talvez contrariando algumas das afirmações sobre aspectos de gênero das "agressões relacionais" (RYS; BEAR, 1997), evidências indicam que meninas, sim, intimidam outros fisicamente e que meninos também fazem fofocas (JUVONEN; WANG; ESPINOZA, 2011; LEVY et al., 2012).

Observar a participação de meninos no bullying homofóbico embasa e desafia algumas das perspectivas do bullying como localizado em traços individuais e como constituído por diferenças categóricas. Ao invés disso, analisar o bullying como parte de um processo de socialização de gênero sugere que essas práticas interacionais podem estar tanto vinculadas a desigualdades estruturais e processos de produção de sentidos de gênero e sexualidade quanto a variáveis individuais.

\section{Bullying Homofóbico}

Quando observados o entendimento e a encenação da masculinidade por parte de homens adolescentes, torna-se bastante evidente que comportamentos que se parecem em grande medida com o bullying são parte central de seu processo de socialização. Os estudos de masculinidade têm mostrado que a homofobia é central no modo como meninos compreendem a si mesmos como homens (KIMMEL, 2001. LEHNE, 1998. KEHILY; NAYAK, 1997. PASCOE, 2007. SCHROCK; SCHWALBE, 2009. SMITH, 1998). De fato, o bullying é em parte um rito de passagem para muitos meninos. E, como tal, sua homofobia é uma homofobia distinta em relação ao gênero. Chamar suas interações de bullying homofóbico sem prestar atenção a seu conteúdo de gênero oculta o modo como o bullying relacionado à sexualidade funciona como um processo de sociabilização para meninos estadunidenses contemporâneos.

As práticas homofóbicas de homens adolescentes geralmente toma a forma de um "fag discourse" ["discurso viado" ou "discurso bichinha"], consistindo de piadas (PASCOE, 2003), vaias, imitações e ameaças através das quais os meninos assinalam publicamente sua rejeição àquilo que é considerado não-masculino. Em outras palavras, $\mathrm{o}$ assédio homofóbico tem a ver tanto com definições da masculinidade quanto com a aversão a homens gays (CORBETT, 2001; KIMMEL, 2001). Esses insultos são aplicados contra meninos que não são masculinos, 
mesmo que só momentaneamente, e meninos identificados como gays (por si mesmos ou pelos outros). Interações como essa estabelecem uma complicada provação diária na qual meninos continuamente se empenham em evitar ser sujeitos de xingamentos, mas são constantemente vulneráveis a eles. No entanto, como pude identificar, observar características individuais de meninos envolvidos nessas práticas não rende percepções significantes sobre o bullying, pois é a prática, e não o indivíduo, aquilo sobre o que devemos prestar mais atenção.

Ao falar com meninos adolescentes na River High sobre o uso que fazem de palavras, eles repetidamente me contaram que "fag" ["viado" ou "bichinha"] é o mais absoluto xingamento para um menino. Um estudante do ensino médio, Darnell, afirmou que "Desde que você é ainda um menino pequeno já te dizem 'não seja uma bichinha"'. Outro aluno, Jeremy contou-me que este insulto literalmente reduzia um menino a nada, "Chamar alguém de gay ou viado é a coisa mais baixa que você pode chamar alguém. Porque isso é como dizer que você não é nada”. Muitos meninos contaram do uso frequente de epítetos como "queer", "gay" e "fag" afirmando isso, como Keith disse "Os meninos são só homofóbicos". No entanto, eles também deixam claro que esta homofobia é relacionada tanto com falhar nas tarefas de masculinidade, quanto com o medo de homens que são realmente homossexuais. Como J. L. disse "Fag [Viado], na verdade, não tem nada a ver com a preferência sexual. Você podia só chamar de idiota, entende? ". Como um adolescente resumiu em uma postagem no Twitter "um faggot [viado] não é um gay; é alguém que age como uma mulher". A homofobia tornase um termo guarda-chuva para qualquer coisa que pode ser enquadrada - mesmo que por um instante - como não-masculina.

Afirmando o predomínio do gênero à definição desses insultos homofóbicos, meninos refletem o que Riki Wilchins chama de Eminem Exception (PASCOE, 2003), em que Eminem explica que ele não chama ninguém de "faggot" ["viado"] devido a sua orientação sexual, mas porque eles são fracos e afeminidos. Embora não seja necessariamente aceitável ser gay, se um homem fosse gay e masculino, ele não mereceria esse rótulo. Se esses meninos são ou não homofóbicos passa a ser discutível diante dessa definição ${ }^{7}$. O que estudos anteriores têm ignorado em ampla medida é que os xingamentos homofóbicos dos meninos tem ao mesmo tempo tudo e nada a ver com suas identidades sexuais. O que é significante aqui é que esses adjetivos homofóbicos desempenham papel central no processo de socialização de gênero desses meninos.

O que torna um menino vulnerável ao epíteto em geral depende de definições locais de masculinidade. Estar sujeito ao assédio homofóbico tem tanto a ver com falhar nas provas de competência da masculinidade, proeza heterossexual ou revelar fraqueza quanto tem a ver com a identidade sexual. Os meninos me contaram que parecer "muito feliz ou alegre", "girar a chave inglesa no sentido errado", ou fazer uma serenata para a namorada, tudo isso poderia deixá-los vulneráveis a xingamentos homofóbicos ${ }^{8}$.

A maneira complexa como meninos usam esses insultos requer que se repense o modo como o debate atual sobre o bullying está abordando a questão. Ou seja, o bullying homofóbico não se trata somente de punir pessoas gays por seu desejo e prática sexuais, é também parte normativa das práticas interacionais de gênero através das quais homens jovens se tornam masculinos.

As formas mais agressivas desse "fagdiscourse" são de fácil reconhecimento. Em geral, espelham a definição de bullying proposta por Olweus (1993). Quando Ricky, estudante de ensino médio gay e transgressor de papeis de gênero na River High, foi insistentemente assediado pelos estudantes populares, heterossexuais e de masculinidade normativa, isso foi imediatamente identificado como bullying. Quando ele participou de um jogo de futebol e seus colegas de turma gritaram coisas como "é uma bicha de merda" ou

7 Dito isso, há acadêmicos que afirmam que por causa do uso desses termos de maneira jocosa são apartados de seu sentido original e assim não são homofóbico (por exemplo, ver: McCORMACK, 2012).

8 Presumidamente uma atividade heterossexual. 
ameaçaram bater nele, isso é claramente bullying 9 . O reconhecimento e enfrentamento deste tipo de bullying aberto é fundamental.

Porém, grande parte do que constitui a homofobia nas relações entre homens jovens é muito menos obviamente identificado como bullying. Para analisar a homofobia dos meninos como forma de socialização de gênero, ao invés de disposição psicológica individual, requer-se a observação do papel que o humor desempenha nessas interações, que essas interações não estão restritas a jovens, e a maneira desigual como as relações de poder são produzidas por interações agressivas em si mesmas. De outra forma se negligenciaria o que vem a ser a maior parte do fenômeno do bullying.

Tomemos a cena famosa do filme "O virgem de 40 anos" (2005), por exemplo, em que se diz "sabe como eu sei que você é gay? ”. Nela, dois amigos heterossexuais caçoam um do outro alternando entre fazer a pergunta "sabe como eu sei que você é gay? ”, e respondê-la, enquanto estão sentados lado a lado jogando videogames violentos em que, a certa altura, um dos jogadores arranca a cabeça do outro. As respostas que dão incluem ouvir Coldplay, Celine Dion, Miami Sound Machine, ou rádio aberta; usar shorts de macramé, gravatas brancas, ternos e coletes, moletons de gola em V; fazer bolinhos de espinafre; assistir programas de TV por assinatura; dirigir carros alugados; não transar; usar implantes dentários; e aparar a barba. Apenas uma pequena minoria das respostas - como fazer sexo com outros homens, "pagar boquete", ter um "saco esfregado na sua cara" - estavam relacionadas com desejo e práticas sexuais. Claramente, nenhum deles realmente acha que o outro é gay, pois ambos se estabeleceram como heterossexuais ao longo do resto do filme. De fato, essas personagens se comportam muito mais como os meninos da River High que disseram não empregar adjetivos homofóbicos por causa da orientação sexual de alguém, mas porque o outro não é viril ${ }^{10}$. Um homem masculino não cozinha determinadas comidas, não escuta tipos específicos de música, não veste algumas roupas em particular, não dirige certos automóveis e, certamente, não dorme com outros homens.

A cena destaca a centralidade do humor no processo da socialização de gênero de homens jovens. Sociólogos têm apontado para a piada como central nas relações entre homens em geral (KEHILY; NAYAK, 1997. LYMAN, 1998). Em diferentes contextos, homens lidam com sua ansiedade relativa à intimidade emocional ou a práticas não-masculinas e consolidam vínculos de amizade com outros através da piada (BRIDGES, 2010). No entanto, pesquisas vêm mostrando que a piada desempenha papel fundamental e pernicioso na identificação dos que estão excluídos de um grupo [outsiders] e na reprodução de desigualdades sociais (BILLING, 2005. BRIDGES, 2010). De fato, o bullying homofóbico que tem lugar entre jovens acontece entre amigos ${ }^{11}$, aparentemente na forma de piadas. Fazer piadas, contudo, não torna as mensagens sobre masculinidade nem um pouco menos graves.

Essa cena também ilustra a maneira como o bullying homofóbico não necessariamente toma lugar em relações estáticas de poder entre homens jovens de alto ou baixo status. Pelo contrário, o insulto pode ir de um menino a outro rapidamente, frequentemente entre amigos (PASCOE, 2007). Isso indica o modo como o desequilíbrio de poder que a definição mais comum de bullying requer é, na verdade, constituído na e pela interação em si. Parte do que acontece nessas interações em forma de piadas é uma luta por dominação na qual um desequilíbrio de poder é criado através do emprego de insultos, independentemente do status dos participantes no momento em que entraram em interação. Reformulando, homens jovens ganham status social ao usar o humor como recurso interacional (HUUKI; MANNINEN; SUNNARI, 2010).

Finalmente, essa cena indica que o tipo de interações homofóbicas em que o objetivo é desmasculinizar o "oponente", seja como forma de diversão, ou não, está longe de se

9 Embora muitos desses exemplos fracassariam no teste de Olweus (1993) já que foram perpetrados por diferentes estudantes. $10 \mathrm{Ou}$ que eles gostariam de tornar a pessoa afeminada.

11 Neste caso, na vida adulta. 
restringir somente à juventude. Embora possa não ficar claro nas pesquisas sobre bullying e homofobia masculina, ambos comportamentos são encontrados também no mundo adulto. Tomemos como exemplo o diretor de uma escola no Arizona que usou de humilhação homofóbica para punir dois meninos por terem brigado, fazendo-os sentar-se em frente à escola de mãos dadas (DOLACK, 2012). Ou observemos a fotografia tirada por membros do exército dos Estados Unidos que rabiscaram a frase "High Jack this Fags [sic]" em uma bomba a ser lançada no Afeganistão durante a operação Enduring Freedom. ${ }^{12}$ A homofobia é uma característica da masculinidade adulta também (bem como o sexismo).

Esses exemplos deinterações dehomensjovens homofóbicos tornam necessária a expansão das discussões atuais sobre o bullying popularmente e academicamente. Interações homofóbicas ocorrem entre meninos de diferentes trajetórias e status. Também acontecem entre amigos íntimos. O humor é ingrediente central dessas interações.

Essas interações não são de modo algum limitadas aos adolescentes. Tem sentidos relativos tanto a gênero quanto sexualidade. Porém, as mensagens sobre socialização de gênero incorporado nessas interações são frequentemente perdidas de vista na maior parte das discussões sobre o bullying homofóbico, o que leva a posicionar tais interações como patológicas, ao invés de considera-las parte normativa da socialização de gênero de meninos.

\section{Uma Sociologia do Bullying}

A abordagem do bullying homofóbico como "fag discourse" indica que esse fenômeno - ao contrário de decorrer do sofrimento emocional (ou apenas dele), de má educação doméstica, falta de educação, ou profunda rejeição ao desejo do mesmo sexo, etc. - é parte normativa de processos de socialização de gênero de meninos.
Isso sugere que, como Finkelhor, Turner e Hamby (2012) afirmam, o debate atual acerca do bullying carece de atenção. Uma sociologia do bullying aponta que esses tipos de trocas agressivas funcionam como reproduções interacionais de desigualdades sociais. Grande parcela da abordagem sobre homofobia tem sido criticada por ser uma compreensão "psicologizada" simplista de um complexo processo social (BRYANT; VIDAL-ORTIZ, 2008; HEREK, 2004; PLUMMER, 1981), também o bullying é uma compreensão individualista de um fenômeno social complicado e, às vezes, contraditório.

\section{Desigualdades estruturais}

Uma sociologia do bullying primeiramente se dedicaria aos tipos de coisas pelas quais crianças são assediadas. Colocando de maneira simples, crianças sofrem bullying por serem diferentes. Mas essas diferenças não são neutras. Em geral, refletem desigualdades estruturais mais amplas. Quando meninos estão envolvidos em bullying homofóbico, estão ensinando uns aos outros uma lição sobre o que significa ser masculino de modo que reflete disparidades legais e culturais. Quando pessoas cujos gêneros variam não são protegidas em 44 estados $^{13}$, esse bullying não parece estar tão desconectado do mundo adulto. Quando discursos de masculinidade são usados para insultar opositores em disputas políticas ${ }^{14}$, é claro que agressões baseadas em gênero envolvendo meninos refletem inquietações nas quais adultos parecem profundamente dedicados. De fato, quando pessoas em relacionamentos homoafetivos são discriminadas no nível federal e quando jovens não aprendem sobre a variação de gênero e identidades não-heteronormativas na escola, é difícil surpreender-se que interajam dessa maneira.

Quando bullying é abordado como uma reprodução interacional da desigualdade social, emerge uma imagem na qual jovens podem ser

12 "High Jack This Fags': Where Gay Men and Lesbians Fit Into the New World Disorder," Democracynow, 93 : 28, October 30, 2001, http://www.democracynow.org/2001/10/30/high_jack_this_fags_where_gay.

13 Há ainda a falta de proteção federal; para mais informações ver: “Transgender Issues: A Fact Sheet” (http://www.transgenderlaw. org/resources/transfactsheet.pdf).

14 Ver por exemplo os discursos de campanhas presidenciais de Kerry contra Bush (FAHEY, 2007). 
vistos como fazendo o trabalho sujo da reprodução social, socializando uns com os outros de modo a aceitar a desigualdade. De muitas maneiras, é um assunto muito mais complicado e grave do que o enquadramento de seu comportamento como chacotas neutras, aleatórias, isoladas ou formas indesejáveis de diferença entre adolescentes. Pensando nessas interações agressivas como a reprodução de desigualdades, pode-se compreendê-las como normativas ao invés de comportamentos patológicos. E quando consideradas sob esta luz, uma sociologia do bullying ilustra que o problema é mais amplo e complexo do que os modelos patológicos o têm feito parecer.

Esse reenquadramento também faz necessário que jovens sejam seriamente compreendidos como atores sociais. Se estão fazendo o trabalho sujo da reprodução social, seu comportamento não poderia ser negligenciado como má tomada de decisões juvenis ou marginalizado pela palavra "bullying". Como sociólogos da juventude apontam, frequentemente não levamos os jovens a sério como atores nos seus próprios mundos sociais, em vez disso os abordamos como seres em processo de se tornar pessoas de fato (CORSARO, 1997). O emprego da palavra "bullying"15 é parte do processo de infantilização e deslegitimação de jovens como atores sociais completos; o que minimiza essas interações, permitindo que adultos estejam cegos ao modo como o bullying geralmente reflete, reproduz, e prepara jovens para aceitar desigualdades incorporadas em estruturas sociais mais amplas.

\section{Interações, não Identidades}

Atualmente, a maior parte da pesquisa sobre o bullying está focada nos indivíduos. Quem é mais provável a se tornar um assediador? Quem é mais provável em ser uma vítima? Minha pesquisa sobre masculinidade de adolescentes sugere que interações devem ser uma unidade de análise igualmente útil. Em vez de observar o tipo de menino que se envolve em um "fag discourse", a pesquisa será mais produtiva quando considerar simultaneamente com o que as interações de bullying se parecem, quando ocorrem, onde, quais atores estão envolvidos, e quais significados sociais são incorporados nelas.

Além de observar as variáveis de nível individual que podem prever agressores e vítimas, pesquisadores devem considerar a interação como uma unidade de análise, que revelaria o bullying como comportamento dinâmico que nem sempre tem a ver com uma vítima e um agressor estáticos. O fato de que ambos possam ter seus lugares alternados - mesmo em uma única interação - é evidência suficiente de que pesquisas baseadas em traços subjetivos só possam nos levar até um certo ponto na compreensão do fenômeno.

Isso tornou-se importante na discussão sobre bullying e violência como a que se seguiu ao massacre de Columbine (no Colorado, em 1999), tendo alguns analistas afirmado que os atiradores foram vítimas de bullying, enquanto outros afirmaram que eles eram assediadores ${ }^{16}$. Priorizar a interação antes do indivíduo leva esse debate a perder sua importância; o contrário inviabiliza a compreensão de como interações agressivas eram parte importante do mundo social naquela escola em particular. Ambos lados discutiram sem encontrar um ponto de convergência, pois apoiaram-se em uma conceptualização de bullying que concebe "assediadores" e "vítimas" como dois grupos distintos. Focando nas interações, ao invés dos indivíduos, podemos entender como ambos lados podem estar corretos e deslocar o foco para uma discussão acerca de soluções do problema.

Embora os relatos populares sobre o bullying quase sempre apresentem formas de agressão realmente assustadoras entre jovens, essas mensagens sobre masculinidade também estão presentes nas interações aparentemente amigáveis entre meninos e homens jovens. Se começarmos a pensar sobre esses tipos de interações como coisas que também acontecem no âmbito da amizade, podemos aproximarmo-nos do entendimento do bullying como fenômeno coletivo e ritualizado, 
e não apenas relativo ao indivíduo. O bullying homofóbico não se trata apenas de uma criança espancando a outra, mas de algo que meninos fazem juntos ${ }^{17}$. Certamente, é a interação em si mesma que pode produzir o desequilíbrio de poder na relação. No entanto, tal desigualdade de status está continuamente a disposição para próximas interações. Embora a palavra "bully"18 dê a entender que há algo psicologicamente errado com o indivíduo que pratica o bullying, esse fenômeno é melhor compreendido quando esses meninos são vistos como colocando em prática as desigualdades estruturais e culturais a partir de suas interações.

\section{Repensando o Bullying}

Por que motivo não abordei o bullying em meu livro especialmente focado em interações homofóbicas de homens jovens? A resposta é que eu estava concentrada na reprodução da desigualdade, algo que não é levado em consideração nos discursos popular e acadêmico atuais sobre o bullying. Pensar sobre o bullying como algo que ocorre nas amizades entre meninos, não só entre inimigos, coloca em questão a perspectiva dominante do bullying como sendo algo que acontece quando um indivíduo se dirige a outro. Observando o bullying dessa maneira sugere que não se trata necessariamente de uma patologia individual (ainda que, obviamente, possa ser), mas também como os pilares das definições de masculinidade. Para levar em conta esse tipo de fenômeno social, o atual debate sobre o bullying precisa ser expandido e reelaborado em sua abordagem. Este artigo sugere que o desenvolvimento de um método sociológico de aproximação ao bullying leva a reenquadrar a discussão sobre interações agressivas entre colegas ao associá-las a questões mais amplas de desigualdade (FINKELHOR et al., 2012).

Uma sociologia do bullying observaria um conjunto de comportamentos sociais agressivos. Esta abordagem levaria a sério a proposta de Finkelhor et al. (2011) para examinar um conjunto de comportamentos violadores - extorsões e retaliações sexuais, psicológicas e emocionais - e os contextos relacionais em que essas violações ocorrem. Além disso, teria de haver uma investigação sobre a desigualdade estrutural e cultural. Feito isso, uma sociologia do bullying poderia reorientar a abordagem de questões como interações sexistas, comentários racistas e humilhação por forma física, como modos de reprodução interacional de desigualdades estruturais e culturais.

Alguns acadêmicos vêm iniciando esse movimento nessa direção intelectual. Nan Stein (2002) reenquadrou o assédio sexual como uma forma de bullying. Elizabeth Meyer (2009) conectou sexismo ehomofobia a comportamentos assediadores na forma de bullying. Hoover e Olson (2000) estão fazendo a mesma coisa em relação às chacotas em geral. Ao invés de ver essas interações agressivas como "motivadas por inclinação" ou do domínio das disposições psicológicas de um indivíduo, uma sociologia do bullying as posicionaria como reprodução interacional de desigualdades raciais, corporais, sexuais e de gênero mais amplas. O que poderia vir a ocorrer através do desenvolvimento de uma sociologia do bullying seria tornar o termo "bully" irrelevante ao indicar que se está separando artificialmente interações agressivas de outras interações ${ }^{19}$.

Esse deslocamento de foco mostraria soluções para o problema do bullying diferentes das que vêm sendo oferecidas. No lugar de políticas de "tolerância zero", aconselhamento psicológico, ou soluções de nível individual, o novo enfoque refletiria a prática e os objetivos de organizações como Gender JUST, o projeto de lei Sylvia Rivera, e Queers for Economic Justice. Essas organizações focam na atuação sobre desigualdades estruturais relativas a gênero e sexualidade de uma perspectiva interseccional. Em vez de 
esperar o bullying escolar "melhorar" ou de ver o casamento gay como uma solução para os males da homofobia, reconhecem que opressões estão conectadas e que lutar contra uma delas demanda necessariamente que se desafie as outras. Dessa maneira, sugiro que intervenções anti-bullying específicas são medidas de curto alcance e que programas, organizações e currículos que foquem em letramento emocional, injustiça social e desigualdade ofereçam caminhos para tratar da mudança social mais efetivos do que os programas focados em medidas preventivas específicas.

Quando se chamam as interações agressivas entre meninos e homens jovens de bullying e se ignora as mensagens sobre desigualdade (por exemplo, a desigualdade de gênero, integrada por relações sérias e jocosas), nos arriscamos a separá-las de questões mais amplas de desigualdade e poder. Ao fazê-lo discursivamente está-se limitando esse tipo de comportamento ao domínio do juvenil, enquadrando-o como um fenômeno no qual os adultos não desempenham nenhum papel, o que lhes permite projetar a culpa sobre as crianças por serem maldosas umas com as outras, ao invés de reconhecer que seu comportamento reflete problemas de desigualdade e preconceito que estão por toda a sociedade (e até mesmo os reforçam). Isso leva adultos a dizerem às crianças que "isso passa", como se o mundo adulto fosse pleno de igualdade e gentileza. E concede à sociedade a possibilidade de se eximir da responsabilidade por perpetuar as desigualdades estruturais e culturais que as crianças estão colocando em prática através de suas interações.

\section{Referências bibliográficas:}

BEATY, Lee A.; ALEXEYEV, Erick B. "The Problem of School Bullies: What the Research Tells Us". In: Adolescence, n 43, 2008, p. I-II.

BENDER, Doris.; LÖSEL, Friedrich. "Bullying at School as a Predictor of Delinquency, Violence and Other Anti-Social Behaviour in Adulthood". In: Criminal Behaviour and Mental Health, $\mathrm{n}^{\circ} 21$, 2011, p.99-106.
BRIDGES, Tristan S. "Men Just Weren't Made to Do This: Performances of Drag at 'Walk a Mile in Her Shoes' Marches". In: Gender and Society, no 24, Fevereiro 2010, p. 5-30.

BILLING, Michael. Laughter and Ridicule: Toward a Social Critique of Humor. Londres: Sage Fine and de Soucey, 2005.

BRYANT, Karl; VIDAL-ORTIZ, Salvador. "Introduction to Retheorizing Homophobias". In: Sexualities, no II, 2008, p. 387-96.

COPELAND, William E.; WOLKE, Dieter.; ANGOLD, Adrian.; COSTELLOM, Jane. "Adult Psychiatric Outcomes of Bullying and Being Bullied by Peers in Childhood and Adolescence". In: JAMA Psychiatry, 2013, p. I-8.

CORBETT, Ken. "Faggot = Loser". In: Studies in Gender and Sexuality, n 2, 2001, p.3-28.

CORSARO, William. The Sociology of Childhood. Londres: Pine Forge Press, 1997.

CULLEN, Dave. Columbine. Nova York: Twelve, Hatchet Book Group, 2009.

DOLACK, Kevin. "Principles Punishes High School Boys with Public Hand Holding". In: ABCnews, 30 de Novembro, 2012.

ERDUR-BAKER, Özgür. "Cyberbullying and its Correlation to Traditional Bullying, Gender and Frequent and Risky Usage of Internet-Mediated Communication Tools". In: New Media \& Society, $\mathrm{n}^{\circ} 12,2010$, p.109-25.

FAHEY, A. C. "French and Feminine: Hegemonic Masculinity and the Emasculation of John Kerry in the 2004 Presidential Race". Critical Studies in Media Communication, $\mathrm{n}^{\circ}$ 24, 2007, p.132-50.

FINKELHOR, D.; TURNER, H.; HAMBY, S. "Questions and Answers about the National Survey of Children's Exposure to Violence". In: Juvenile Justice Bulletin, Washington, DC: U.S. Government Printing Office, 2011, p. I-4.

FINKELHOR, David.; TURNER, Heather A.; 
HAMBY, Sherry. "Let's Prevent Peer Victimization, Not Just Bullying". Child Abuse and Neglect, $\mathrm{n}^{\circ}$ 36, 2012, p.21.

FINKELHOR, David. Trends in Bullying and Peer Victimization. Durham: Crimes Against Children Research Center, 2013.

FRISÉN, Ann; JONSSON, Anna-Karin; PERSSON, Camilla.. "Adolescents' Perception of Bullying: Who is the Victim? Who is the Bully? What Can Be Done to Stop Bullying?". In: Adolescence, $\mathrm{n}^{\circ}$ 42, inverno, 2007, p.749-61.

GRIFFITHS, L. J.; WOLKE, D.; PAGE, A. S.; HORWOOD, J. P. "Obesity and Bullying: Different Effects for Boys and Girls". In: Archives of Disease in Childhood, no 91, 2005, p.121-5.

HEREK, Gregory M. "Beyond Homophobia': Thinking about Sexual Prejudice and Stigma in the Twenty-First Century". In: Sexuality Research and Social Policy, n' I, 2004, p.6-24.

HILTON, Jeanne M.; ANNGELA-COLE, Linda.; WAKITA, Juri. "A Cross-Cultural Comparison of Factors Associated with School Bullying in Japan and the United States". In: Family Journal, n ${ }^{\circ} 18$, 2010, p.413-22.

HOOVER, H; OLSON, G. "Sticks and Stones May Break Their Bones: Teasing as Bullying". In: Reclaiming Children and Youth: Journal of Strength-Based Interventions, no 9, 2000, p.87-91.

HUUKI, Tuija.; MANNINEN, Sari.; SUNNARI, Vappu. "Humour as a Resource and Strategy for Boys to Gain Status in the Field of Informal School". In: Gender \& Education, n 22, 2010, p.369.

IT GETS BETTER PROJECT. "What is the It Gets Better Project?". In: It Gets Better Project, n' $\mathrm{I}$, Março, 2013.

JUVONEN, J.; WANG, Y.; ESPINOZA, G. "Bullying Experiences and Compromised Academic Performance Across Middle School Grades". In: Journal of Early Adolescence, no 31, 2010, p.152-73.
KEHILY, Mary Jane.; NAVAK, Anoop. "Lads and Laughter': Humour and the Production of Heterosexual Masculinities". In: Gender and Education, no9, 1997, p. 69-87.

KEHLER, Michael D. "Hallway Fears and High School Friendships: The Complications of Young Men (Re)negotiating Heterosexualized Identities". In: Discourse: Studies in the Cultural Politics of Education, $\mathrm{n}^{\circ}$ 28, 2007, p.259-77.

KIMMEL, Michael. "Masculinity as Homophobia: Fear, Shame, and Silence in the Construction of Gender Identity". In: WHITEHEAD, S.; BARRETT, F. (eds.). The Masculinities Reader. Cambridge, MA: Polity Press, 2001, p.266-87.

KIMMEL, Michael.; MAHLER, Matthew. "Adolescent Masculinity, Homophobia, and Violence: Random School Shootings, 1982-2001". In: American Behavioral Scientist, $\mathrm{n}^{\circ}$ 46, Junho, 2003, p.1439-58.

KLEIN, Jessie. The Bully Society. Nova York: New York University Press, 2012.

LEHNE, Gregory. "Homophobia among Men: Supporting and Defining the Male Role". In: KIMMEL, M.; MESSNER, M. (eds.). Men's Lives. Boston: Allyn and Bacon, 1998, p. 237-49.

LEVY, Nathaniel.; CORTESI, Sandra.; GASSER, Urs.; CROWLEY, Edward.; BEATON, Meredith.; CASEY, June.; NOLAN, Caroline. Bullying in a Networked Era: A Literature Review. Cambridge, MA: Berkman Center for Internet and Society Research Publication Series, 2012, p. 2012-17.

LI, Qing. "Cyberbullying in Schools: A Research of Gender Differences". In: School Psychology International, $\mathrm{n}^{\circ} 27,2006$, p. 157-70.

LYMAN, Peter. "The Fraternal Bond as a Joking Relationship: A Case Study of the Role of Sexist Jokes in Male Group Bonding". In: KIMMEL, M.; MESSNER, M. (eds.). Men's Lives. Boston: Allyn and Bacon, 1998, p.171-93.

MARWICK, Alice E.; BOYD, Danah. "The Drama! Teen Conflict, Gossip, and Bullying in 
Networked Publics". Comunicação apresentada em A Decade in Internet Time: Symposium on the Dynamics of the Internet and Society, 2012.

MCCORMACK, Olweus. The Declining Significance of Homophobia: How Teenage Boys are Redefining Masculinity and Heterosexuality. Nova York: Oxford University Press, 2012.

MEYER, Elizabeth. Gender, Bullying, and Harassment: Strategies to End Sexism and Homophobia in Schools. Nova York: Teachers College Press, 2009.

NANSEL, Tonja R.; OVERPECK, Mary.; PILLA, RamaniS.; RUAN, J.;SIMONS-NORTON, Bruce.; SCHEIDT, Peter. "Bullying Behaviors Among US Youth". JAMA: Journal of the American Medical Association, $\mathrm{n}^{\circ}$ 285, 2001, p.2094-100.

\section{NATIONAL MENTAL HEALTH ASSOCIATION. What Does Gay Mean? Teen Survey Executive Summary, 2002.}

OLWEUS, Dan. Bullying at School: What We Know and What We Can Do. Malden, MA: Blackwell, 1993.

PASCOE, C. J. Dude, You're a Fag: Masculinity and Sexuality in High School. Berkeley e Los Angeles: University of California Press, 2007.

"Multiple Masculinities? Teenage Boys Talk about Jocks and Gender". In: American Behavioral Scientist, $\mathrm{n}^{\circ}$ 46, 2003, p.1423-38.

PEETERS, Margot.; CILESSEN, Antonius.; SCHOLTE, Ron. "Clueless or Powerful? Identifying Subtypes of Bullies in Adolescence". In: Journal of Youth and Adolescence, n 39, 2010, p.1041-52.

PESKIN, Melissa Fleschler.; TORTOLERO, Susan R.; MARKHAM, Christine M. "Bullying and Victimization among Black and Hispanic Adolescents". In: Adolescence, no 41, 2006, p. 46784.

PLUMMER, Kenneth. The Making of the Modern Homosexual. Londres: Hutchinson, 1981.

POTEAT, V. P.; RIVERS, Ian. "The Use of
Homophobic Language Across Bullying Roles During Adolescence". In:Journal of Applied Developmental Psychology, no 31, 2010, p. 166-72.

POTEAT, V.P.; KIMMEL, MichaelS.; WILCHINS, Riki. "The Moderating Effects of Support For Violence Beliefs on Masculine Norms, Aggression, and Homophobic Behavior During Adolescence". In: Journal of Research on Adolescence, no 21, 2011, p.434-47.

PUHL, Rebecca.; PETERSON, Jamie Lee.; LUEDICKE, Joerg. "Weight-Based Victimization: Bullying Experiences of Weight Loss TreatmentSeeking Youth". In: Pediatrics,2012, p. I-9.

PUHL, Rebecca.; LUEDICKE, Joerg. "WeightBased Victimization Among Adolescents in the School Setting: Emotional Reactions and Coping Behaviors". In: Journal of Youth \& Adolescence, $\mathrm{n}^{\circ}$ 41, 2012, p.27-40.

RYS, Gail S.; BEAR, George G. "Relational Aggression and Peer Relations: Gender and Developmental Issues". In: Merrill-Palmer Quarterly(1982-), no 43, Janeiro,1997, p. 87-106.

SCHROCK, Douglas; SCHWALBE, Michael. "Men, Masculinity, and Manhood Acts". In: Annual Review of Sociology, no 35, 2009, p. 27795.

SALMIVALLI, Christina.; VOETEN, Marinus. "Connections Between Attitudes, Group Norms, and Behaviour in Bullying Situations". In: International Journal of Behavioral Development, $\mathrm{n}^{\circ} 28,2004$, p.246-58;

SEALS, Dorothy.; YOUNG, Jerry. "Bullying and Victimization: Prevalence and Relationship to Gender, Grade Level, Ethnicity, Self-Esteem, and Depression". In: Adolescence, no 38 (Winter 2003):735-47.

SMITH, George W. "The Ideology of 'Fag': The School Experience of Gay Students". In: Sociological Quarterly, no 39, 1998, p. 309-35.

STEIN, Nan. "Bullying as sexual harassment". In: BAILEY, Susan M. (org.). The Jossey-Bass Reader 
on Gender in Education. São Francisco: JosseyBass, 2002, p. 409-28.

STUART-CASSEL, V.; BELL, A.; SPRINGER, J. F. "Analysis of State Bullying Laws and Policies". In: U.S. Department of Education, 2011.

THURLOW, Crispin. "Naming the 'Outsider Within': Homophobic Pejoratives and the Verbal Abuse of Lesbian, Gay and Bisexual High-School Pupils". In: Journal of Adolescence, $\mathrm{n}^{\circ}$ 24, 2001, p. 25-38.

VAILLANCOURT, Tracy; HYMEL, Shelley.; McDOUGALL, Patricia. "Bullying is Power: Implications for School-Based Intervention Strategies". In: Journal of Applied School Psychology, no 19, 2013, p.157-76;

YBARRA, Michele L.; BOYD, Danah.; KORCHMAROS, Josephine.; OPPENHEIM, Jay. "Defining and Measuring Cyberbullying within the Larger Context of Bullying Victimization". In: Journal of Adolescent Health, no 51, 2012, p.5358 . 
